\title{
Duchenne muscular dystrophy and Duane's syndrome: a rare association
}

\author{
Distrofia muscular de Duchenne e síndrome de Duane: uma rara associação \\ Livia M.A. Pasqualin', Edmar Zanoteli', Marco A.M. Veloso', Silvana K. Frizzo', Maria B.D. Resende', \\ Julio Z. Abucham-Neto², Mariza Polati ${ }^{2}$, Gerson Chadi ', Umbertina C. Reed ${ }^{1}$
}

\begin{abstract}
'Department of Neurology, Medical School of the University of São Paulo, São Paulo SP, Brazil;
${ }^{2}$ Department of Ophthalmology, Medical School of the University of São Paulo, São Paulo SP, Brazil.
\end{abstract}

Correspondence: Lívia MA Pasqualin; Department of Neurology, Medical School of the USP; Avenida Dr. Enéas de Carvalho Aguiar 255 / sala 5131;05403-000 São Paulo SP - Brasil; E-mail: liviameirelles@uol.com.br

Conflict of interest: There is no conflict of interest to declare.

Received 12 June 2012; Accepted 20 June 2012

Duane retraction syndrome is a form of strabismus with a unilateral or bilateral congenital anomaly of the $6^{\text {th }}$ cranial nerve nuclei with aberrant innervations by supply from the 3rd cranial nerve ${ }^{1-3}$. It is characterized by limited eye abduction (type I), adduction (type II) or both (type III), and eyeball retraction with associated narrowing of the palpebral fissure during adduction of the eye. It is a rare condition affecting $0.1 \%$ of the population ${ }^{2}$. Only $30 \%$ of cases are associated with other malformations, mostly those that affect ears, kidneys, heart or upper limbs 4 .

\section{CASE REPORT}

A 5-year-old boy was diagnosed with strabismus during the first year of life. He developed appropriate milestones of neuropsychomotor development, with gait acquisition at the age of 1 year and frequent falls since then. After turning 2 years old, increased weakness was evident, especially to climb stairs. Ophthalmological examination showed a head turn of 10 degrees to the left, retraction of the eyeball in adduction, bilateral limited abduction and adduction of the eyes, and slight narrowing of the right palpebral fissure during adduction. Regarding the abduction of the left eye, a slight widening of the palpebral fissure was observed in the left eye, characterizing bilateral type III Duane retraction syndrome, with esotropia and normal CA/A.

A test was performed for Duchenne muscular dystrophy (DMD) gene deletions using multiplex PCR to examine 26 exons of the DMD gene and no deletion was found. The serum creatine phosphokinase was 90 times higher than the upper limit of normal value. Muscle biopsy showed a dystrophic pattern, with dystrophin protein deficiency on immunohistochemical reaction (Fig A-C). Orbital MRI demonstrated preservation of the entire extrinsic muscles of the eye and the nervus abducens (Fig D).

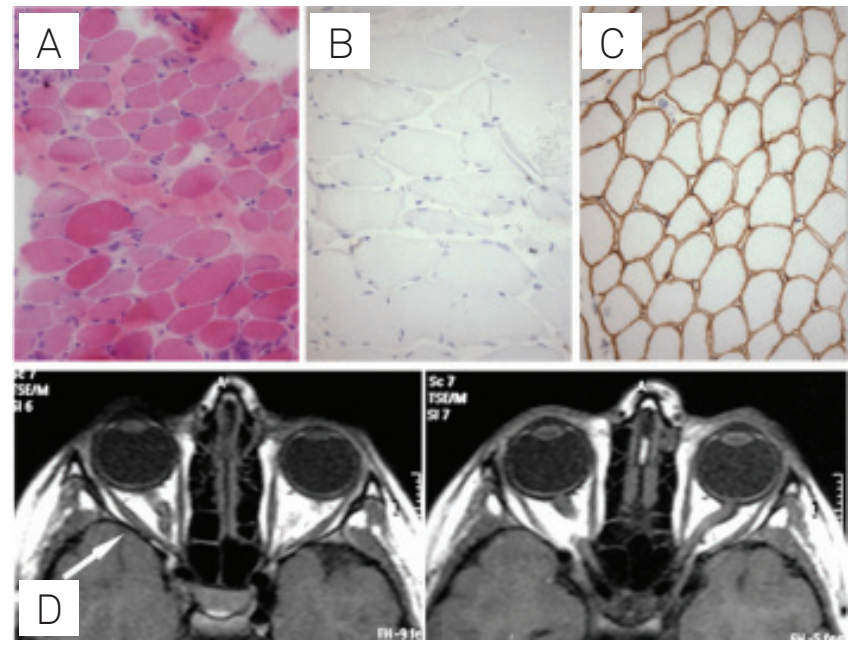

Fig. Orbital magnetic resonance imaging (MRI) and muscle biopsy in the child with Duchenne muscular dystrophy and Duane retraction syndrome. (A) Myopathic changes characterized by fiber size variability, increase of the connective tissue, necrosis and regenerating fibers (transverse sections on H\&E). (B) Complete deficiency of dystrophyn immunostaning on sarcolemm of the fibers compared to the normal control (C). (D) Normal aspect of the ocular muscles (arrow) on orbital MRI.

\section{DISCUSSION}

A case in which DMD was associated with unilateral type I Duane syndrome has been previously reported only once ${ }^{1-5}$. There is a progressive degeneration of the muscle fibers that causes increasing weakness and accentuated elevation of serum creatine phosphokinase level. The molecular analysis of DMD gene was negative for deletions, therefore, most probably the patient presents some punctual mutation that was not studied.

Many forms of myopathies cause limitation of eye movement due to primary muscle involvement. However, clinical 
and histological preservation of the extraocular musculature in DMD is well known. In myopathies, including DMD, skeletal muscle involvement can be seen through the identification of increased T1WI signal on muscle tissue due to fatty infiltration ${ }^{5}$. In the ocular muscles of our patient, changes on MRI were not observed. Thus, ocular impairment was probably caused by the involvement of the nervous system.

Initially described as having a myopathic origin, most recent studies are controversial concerning the etiology of Duane's syndrome. While some studies based on the MRI did not identify lateral rectus muscle abnormalities ${ }^{5}$, others have demonstrated changes in the development of the motor nucleus of the nervus abducens and anomalous innervation of the lateral rectus muscle, thus indicating the neurogenic origin of the condition ${ }^{4-5}$. Although the association of DMD and Duane's syndrome in the same patient is likely to be a concidence, the purpose of this report is to draw attention to the variety of clinical signals that might hamper the final diagnosis.

\section{ACKNOWLEDGEMENTS}

We are grateful to the patient and his family for their participation.

\section{References}

1. Mohan K, Sharma A, Pandav SS. Differences in epidemiological and clinical characteristics between various types of Duane retraction syndrome in 331 patients. J AAPOS 2008;12:576-580.

2. Yüksel D, Orban de Xivry JJ, Lefèvre P. Review of the major findings about Duane retraction syndrome (DRS) leading to an updated form of classification. Vision Res 2010;50:2334-2347.

3. Zanin E, Gambarelli N, Denis D. Distinctive clinical features of bilateral Duane retraction syndrome. J AAPOS 2010;14:293-297.
4. Honda $Y$, Yoshioka M. Duane $\$$ s retraction syndrome associated with muscular dystrophy. J Pediatr Ophtalmol Strabismus 1978;15: 157-159.

5. Yonghong J, Kanxing Z, Zhenchang W, et al. Detailed magnetic resonance imaging findings of the ocular motor nerves in Duane $\$ s$ retraction syndrome. J Pediatr Ophthalmol Strabismus 2009;46: 278-85; quiz: 286-287. 